\title{
Primary intra medullary inter locking nailing for open tibia fractures a prospective analysis of functional and radiological outcome
}

\author{
Mohamed Ashraf Ali ${ }^{1}$, Manikandan Adimoolam ${ }^{2 *}$, Haseena Banu ${ }^{3}$
}

\begin{abstract}
${ }^{1}$ Department of Orthopaedics, Dhanalakshmi Srinivasan Medical College, Perambalur, India
${ }^{2}$ Department of Orthopaedics, Sri Venkateshwara Medical College and Research Center, Pondicherry, India

${ }^{3}$ Shifa Multi Specialty Hospital, Dindigul, Tamil Nadu, India
\end{abstract}

Received: 20 April 2021

Revised: 01 May 2021

Accepted: 04 May 2021

\section{*Correspondence:}

Dr. Manikandan Adimoolam,

E-mail: drmanikandanadimoolam@gmail.com

Copyright: $\odot$ the author(s), publisher and licensee Medip Academy. This is an open-access article distributed under the terms of the Creative Commons Attribution Non-Commercial License, which permits unrestricted non-commercial use, distribution, and reproduction in any medium, provided the original work is properly cited.

\begin{abstract}
Background: Tibia is the most commonly fractured long bone in the body encountered in today's practice. The use of non-operative treatment of tibial fractures is associated with a high prevalence of malunion, joint stiffness and poor functional outcome. This study was conducted to analyze the functional and radiological outcome of patients treated for open fractures of tibia with primary intramedullary interlocking nailing within 24 hours of injury.

Methods: From October 2013 to May 2015, a prospective and descriptive study was done where 30 consecutive patients with open tibial fractures was treated with primary intramedullary interlocking nailing within 24 hours of injury, at Pondicherry institute of medical sciences, Pondicherry. Functional outcome was assessed using Karlstrom and Olerud scores and radiological outcome was assessed by radiographic union scale of tibial fractures (RUST) scores at 6 weeks, $3 \mathrm{rd}$, 6th, 9th and 12th month post-operatively. Intra-operative and post-operative complications were noted and documented. The results were analyzed using SPSS software.

Results: The most common age group who presented was between 18-30 years and the average age was 36.7 years. $36.67 \%$ had grade I injury, $40 \%$ had grade II injury, meanwhile, grade IIIA injuries constituted $20 \%$ and grade IIIB injuries constituted $3.33 \%$. The average functional score was 33.33 which showed overall good result. The average RUST score was found to be 11.33 denoting union.

Conclusions: Hence, we observed that intramedullary interlocking nailing is a good procedure in terms of functional and radiological outcome if done within 24 hours of injury.
\end{abstract}

Keywords: Open fracture, Tibia shaft fractures, IMIL nailing

\section{INTRODUCTION}

Tibia being is a major weight bearing bone of the body. The knee joint with anatomical restriction in rotational movements is highly prone for fracture in twisting injuries. Management of tibial fractures has evolved over the time and presently surgical fixation is the widely accepted treatment modality with lesser complications in case of closed fractures. ${ }^{1}$ But the management of open tibia fractures is difficult and widely debatable. With infection being the most dreaded complication in any surgery, managing open tibia fracture with internal fixation is still controversial. ${ }^{2}$ Other modalities like using an external fixator such as Ilizarov or LRS as definitive fixation device are also commonly practiced. But they have their own drawbacks and complications. ${ }^{3}$ A two staged procedure with initial external fixation and secondary internal fixation is the most preferred option in open fractures. Primary IMIL nailing even though advocated has still not been fully accepted mainly due to the fear of infection. Invariably primary debridement plays an important role in management of these fractures. Objective of this study was 
to evaluate the functional and radiological outcome of primary wound debridement and IMIL nailing in open tibia fracture which present to us early within 24 hours of injury, using Karlstorm and Oleraud scoring and RUST scoring.

\section{METHODS}

This study was done as a prospective randomized descriptive study. A minimum sample size of 30 was calculated based on the study by Agarwal et al. ${ }^{4}$ After obtaining ethical clearance from the college ethical committee, patients presenting with open tibia fracture to Pondicherry institute of medical science from October 2013 to May 2015 were selected. They were graded based on Gustilo and Anderson grading. Patients satisfying the inclusion and exclusion criteria were selected for the study.

\section{Inclusion criteria}

Open tibial fractures (grade I, II, III A and III B of Gustilo Anderson classification, adults of both sexes, skeletally mature patients $>18$ years, patients operated within 24 hours of injury were included in the study.

\section{Exclusion criteria}

Gustilo Anderson grade III C open injuries, patients with associated head injury, poly trauma patients, patients medically unfit for surgery (associated co-morbidities) and those with intra articular fractures were excluded in the study.

All patients were given a primary wound lavage in the emergency room and splinted. All the patients were started on prophylactic antibiotics. Plastic surgery opinion was taken in needed cases. Once patient consented, they were taken up for emergency wound debridement and primary IMIL nailing at the earliest, within 24 hours.

\section{Surgical procedure}

Under spinal anesthesia, patient in supine position and tourniquet control a through betadine scrub and wash given. Under sterile aseptic precautions, the open wound was debrided and lavage given with adequate saline. The wound was extended in cases for complete exposure and lavage. Once wound debrided thoroughly, through a transpatellar tendinous approach, medullary canal entry made using a curved awl. Ball tip guide wire inserted under carm guidance and passed across the fracture site. Serial reaming of the medullary canal done in increments of 0.5 $\mathrm{mm}$ with knee in hyper flexion hanging by the side of the table. Ball tip guide wire exchanged with plain guide wire. The desired size nail inserted while a skilled assistant holds the fracture reduction. Distal locking is done with the limb in figure of 4 position using c-arm guidance. In necessary cases compression at fracture site was achieved by reverses malleting. Proximal locking done the jig removed. Thorough wash given and all incisions closed in layers with a suction drain at the open wound site. Primary closure was possible in 29 patients with one patient needing soft tissue cover, done by plastic surgery team.

Post operatively patients were closely monitored with limb elevation and vitals charting. Radiological evaluation was done. IV antibiotics were continued for a period of 1 week in average. Wound inspection was done on post-op day (POD) 2 and drain removal done. Patients were encouraged to do knee range of movement exercise, quadriceps strengthening exercise and partial weight bearing walking as early as 2nd POD. Full weight bearing walking was usually delayed to 6 weeks. Regular dressing and serial wound inspection was done to look for signs of infection. Suture removal was delayed till 14 days. Dynamisation was done in necessary cases.

Patients were assessed using Karlstorm and Oleraud scoring and RUST scoring at 6 weeks, 3 months 6 months and 1 year post operatively. Parameters such as type of wound, mode of injury, time taken for the soft tissues to heal, number of procedures needed for the soft tissue to cover, additional procedures needed like bone grafting/dynamization, time taken for bony union, complications like malunion, non-union, functional outcome and radiological outcome were studied. The data was statically analyzed using SPSS 16.0 and appropriate statistical tests. Outcomes were analyzed using student $t$ test.

\section{RESULTS}

In our study, 30 patients between the age group of 18 years to 75 years were included (Table 1). 22 patients were male and 8 were female. RTA was the found to be most common mode of injury with 26 patients. According to Gustillo Anderson grading, 11 patients were type I, 12 patients were type II and 7 patients were type IIIA/IIIB. Right side was the most common side involved $66.7 \%(n=20)$. The average period of follow up was 14 months (6-22 months). No patients were lost during follow up. Patients were evaluated using Karlstrom Olerud score and RUST score. Out of the 30 patients, 8 patients were found to have excellent functional score and 13 patients had good outcome 5 patients had. We found that there was no significant difference between the functional scores of grade I and grade II type of fractures $(\mathrm{p}=0.205)$ and grade I and III type of fractures $(\mathrm{p}=0.06)$. According to RUST score, 28 patients had good rate of union. 2 patients who had grade III open fracture patients had poor outcome. We found that there was no significant difference between the RUST scores of grade I and grade II type of fractures $(p=0.842)$ and grade I and III type of fractures $(p=0.565)$. Most common complication was infection and non-union in 2 patients. They were managed by secondary wound debridement and bone grafting. 
Table 1: Age group.

\begin{tabular}{|ll|}
\hline Age group (in years) & Number of patients (\%) \\
\hline $\mathbf{1 8 - 3 0}$ & $11(36.7)$ \\
\hline $\mathbf{3 1 - 4 0}$ & $5(16.7)$ \\
\hline $\mathbf{4 1 - 5 0}$ & $2(6.7)$ \\
\hline $\mathbf{5 1 - 6 0}$ & $7(23.3)$ \\
\hline $\mathbf{6 1}$ and above & $5(16.7)$ \\
\hline
\end{tabular}

Table 2: Gustilo Anderson grading.

\begin{tabular}{|ll|}
\hline $\begin{array}{l}\text { Gustilo Anderson } \\
\text { grading }\end{array}$ & Number of patients \\
\hline Grade I & 11 \\
\hline Grade II & 12 \\
\hline Grade IIIA & 6 \\
\hline Grade IIIB & 1 \\
\hline
\end{tabular}

Table 3: Functional score.

\begin{tabular}{|ll|}
\hline $\begin{array}{l}\text { Karlstorm Olerud } \\
\text { scoring }\end{array}$ & Number of patients \\
\hline Excellent & 8 \\
\hline Good & 13 \\
\hline Acceptable & 5 \\
\hline Moderate & 2 \\
\hline Poor & 2 \\
\hline
\end{tabular}

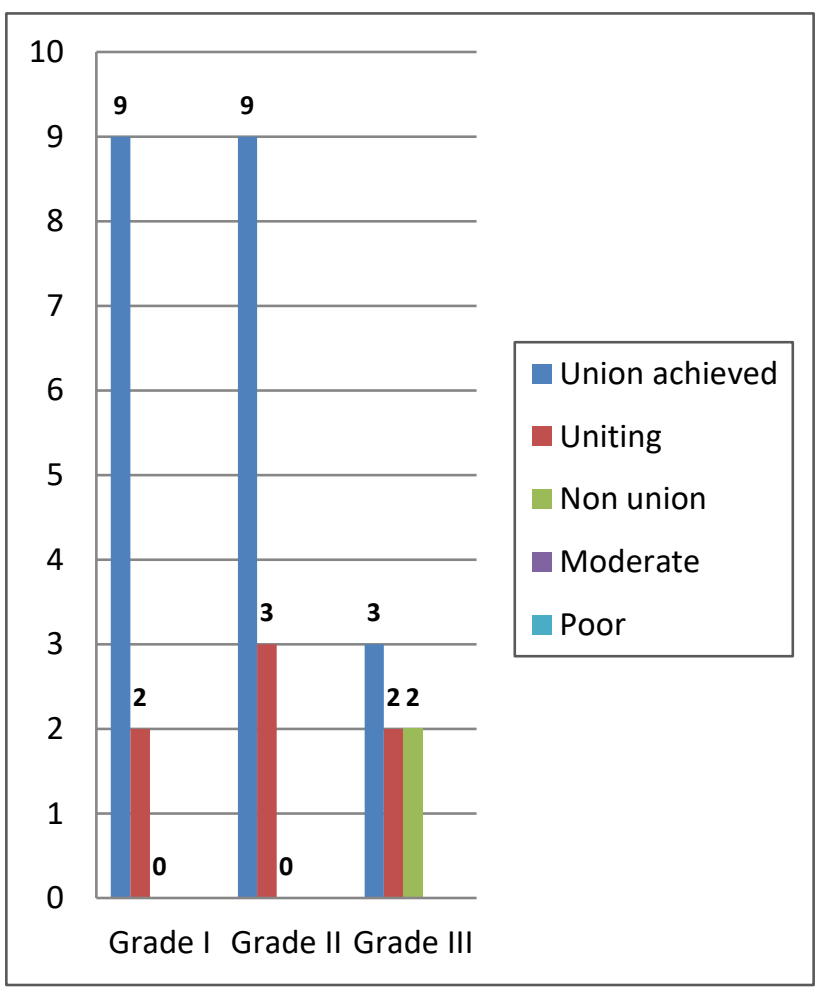

Figure 1: RUST score.

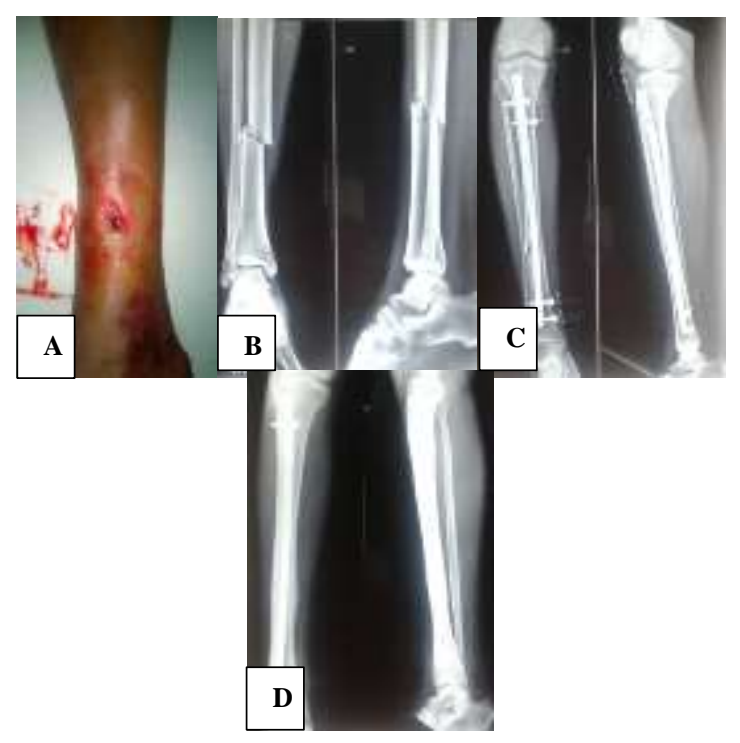

Figure 2: Pre and post-op images of type I tibia fracture; (A) type 1 open wound; (B) pre-op X-ray;

(C) post-op X-ray; (D) 1 year follow up united fracture.

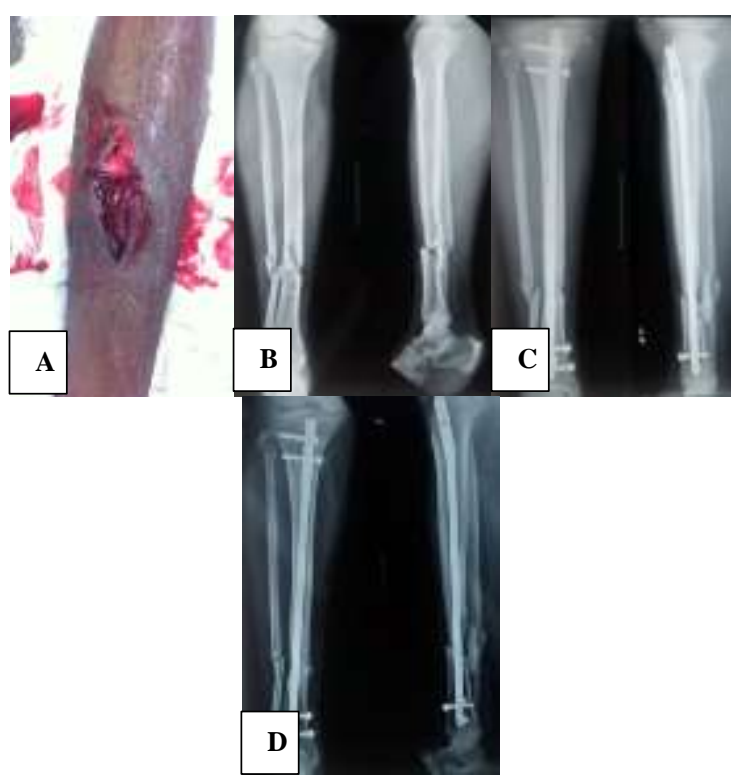

Figure 3: Type III open fracture; (A) open wound; (B) pre-op X-ray; (C) post-op X-ray; (D) 3 months follow up.

\section{DISCUSSION}

Management of open tibia fracture is difficult and challenging. Multiple factors like degree of contamination, soft tissue and bone loss, fracture pattern and communition play a major role in the outcome. Risk of infection being the major deciding factor in the management, most preferred treatment modality is primary stabilization with external fixator with wound management and a secondary definitive fixation based on the wound status. Even though risk of infection is reduced, external fixtation has its own complications and de merits. ${ }^{5}$ Golubović et al showed that 
complications such as osteitis (infection), non-union, pin site infection, malunion are common with external fixation devices. In addition to these, other factors such as prolonged duration of treatment and need for a secondary procedure and also the tolerance with the external fixation has its own detrimental effect on the overall outcome. Shanon et al showed that $23.3 \%(n=7)$ needed re-surgery in external fixator group compared $6.67 \%(n=2)$ needed resurgery in un-reamed nailing. ${ }^{6}$ Henley et al concluded that IMN was more stable and effective in maintaining the alignment compared to external fixator. ${ }^{7}$

Internal fixation can overcome most of these problems if done early along with thorough debridement and wound lavage. Even though this reduces the complications, many factors influence the final outcome. The timing of the primary surgery since injury plays a major role in the outcome. In the past the golden period for fixing an open fracture was considered to be 8 hours from injury. ${ }^{4}$ This study was intended to analyze the options of early wound debridement and primary IMIL nailing in patients who presented to us with open tibia fracture within 24 hours of injury.

Reaming is another debatable topic when treating an open fracture. Common belief is that the chance of infection increases with reaming. But this has not been proved absolutely true. Yokohoma et al in his study has showed that canal reaming did not increase the complication like infection. ${ }^{8}$ In our study reaming was done in all cases. A thorough debridement at the fracture site clearing it of any contaminations is the major factor. The rate of infection did not increase with reaming. Papakostidis et al showed that undreamed and reamed nailing both had similar rate of infection. ${ }^{9}$

Of the 30 patients in our study 21 patients showed excellent/good function outcome. ${ }^{5}$ Patients had acceptable functional outcome. 2 patients had moderate outcome and 2 patients had poor outcome. The average functional score at 6 weeks was found to be 25.67 and at 12 months was 32.33. Ashwin et al showed good functional outcome in $90 \%$ of the cases involving type I and II open fractures. ${ }^{10}$ In our study we achieved good functional outcome in $86.6 \%(n=26)$ patients which was comparable with other studies. Our study included type III A/B fractures. Agarwal et al in his study showed excellent results in $60 \%$ and good result in $23 \%$, which was comparable with our study. ${ }^{4}$

RUST score was used for analysis of radiological union. The average RUST score at 1 year was 11.44. Patients with RUST score at 3 months follow up of 6 or less had more risk of non-union than with RUST score 7 or more. ${ }^{11}$ In our study 2 patients had a RUST score less than 3 at months follow up. Both these patients had infections at the fracture site and needed secondary debridement.

In our study, we had 2 patients with superficial infection $(6.67 \%)$ and 2 patients with deep infection and non-union
(6.67\%). Ashwin et al had similar infection rates in type I and II open fractures. ${ }^{10}$ Agarwal et al had $10 \%$ infection in type III open fractures operated within 48 hours after injury. ${ }^{4}$ Gustilo and Anderson reported $2-16 \%$ rate of infection in type III fractures. ${ }^{12}$ Papakostidis et al in his study conclude that grade III B open fractures has higher chances of infection compared to other grades. ${ }^{9}$ Patients with superficial infection settled with regular dressing and IV antibiotics. Deep infection was seen in patient with type III open fracture. They needed secondary surgical debridement and bone grafting. Most common organism was staphylococcus aerus in 3 patients and streptococcus in 1 patient.

In our study, 7 patients need dynamization. 2 patients who had deep infection needed re-surgery, wound debridement and bone grafting. 1 patient went for mild valgus malunion. We did not come across any other complications like compartment syndrome, stiffness, DVT, implant failure, anterior knee pain in our study. Compartment syndrome was seen more commonly with grade II fractures. ${ }^{9}$ In our study since we did not face any compartment syndrome. This may be attributed to extending the open wound site for thorough debridement. Early mobilization was started in all cases hence we did not face any stiffness or DVT.

A major limitation of the study was the smaller sample size. The number of cases comprising grade III injuries was only $23 \%$ in our study of which 2 patients had infection and non-union. Further studies with a larger sample size of grade III fractures are necessary to fully evaluate the outcome of IMIL nailing in grade III open fractures.

\section{CONCLUSION}

Patients with open tibia fractures warrant an emergency intervention. Primary wound debridement plays an important role and when done within 24 hours has less chance of infection. Internal fixation with an IMIL nail provides a stable fixation. We conclude that early wound debridement and internal fixation is a good option in patients presenting within 24 hours of injury. With good union rates and lesser complication and avoiding a second surgery, it may be considered in patients who present within 24 hours of injury. RUST score at 3 months is a reliable indicator of fracture union.

\section{Funding: No funding sources \\ Conflict of interest: None declared}

Ethical approval: The study was approved by the institutional ethics committee

\section{REFERENCES}

1. Hooper GJ, Keddell RG, Penny ID. Conservative management or closed nailing for tibial shaft fractures. A randomised prospective trial. J Bone Joint Surg Br. 1991;73(1):83-5. 
2. Bone LB, Johnson KD. Treatment of tibial fractures by reaming and intramedullary nailing. J Bone Joint Surg. 1986;68:877-86.

3. Hao ZC, Xia Y, Xia DM, Zhang YT, Xu SG. Treatment of open tibial diaphyseal fractures by external fixation combined with limited internal fixation versus simple external fixation: a retrospective cohort study. BMC Musculoskelet Disord. 2019;20(1):311.

4. Agrawal A, Chauhan VD, Maheshwari RK, Juyal AK. Primary nailing in the open fractures of the tibiais it worth? J Clin Diagn Res. 2013;7(6):1125-30.

5. Golubovic Z, Stojiljkovic P, MacukanovicGolubovic L, Milic D, Milenkovic S, Kadija M, et al. External fixation in the treatment of open tibial shaft fractures. Vojnosanit Pregl. 2008;65(5):343-8.

6. Shannon FJ, Mullett H, O'Rourke K. Unreamed intramedullary nail versus external fixation in grade III open tibial fractures. J Trauma. 2002;52(4):650-4.

7. Henley MB, Chapman JR, Agel J, Harvey EJ, Whorton AM, Swiontkowski MF. Treatment of II, IIIA and IIIB open fractures of the tibial shaft: a prospective comparison of unreamed interlocking intramedullary nails and half-pin external fixators. J Orthop Trauma. 1998;12:17.

8. Yokoyama K, Itoman M, Uchino M, Fukushima K, Nitta H, Kojima Y. Immediate versus delayed intramedullary nailing for open fractures of the tibial shaft: a multivariate analysis of factors affecting deep infection and fracture healing. Ind $\mathbf{J}$ Orthop. 2008;42(4):410-9.

9. Papakostidis C, Kanakaris NK, Pretel J, Faour O, Morell DJ, Giannoudis PV. Prevalence of complications of open tibial shaft fractures stratified as per the Gustilo-Anderson classification. Injury. 2011;42(12):1408-15.

10. Shetty A, Rai H, Mathias LJ. Management of open fractures of shaft of tibia in adults using interlocking intramedullary nailing. Int $\mathrm{J}$ Biol Med Res. 2012;3(2):1768-70.

11. Mundi R, Axelrod D, Chaudhry H, Sahota N, HeelsAnsdell D, Sprague S, et al. Association of threemonth radiographic union score for tibia fractures (rust) with nonunion in tibial shaft fracture patients. Cureus. 2020;12(5):8314.

12. Gustilo RB, Anderson JT. Prevention of infection in the treatment of one thousand and twenty-five open fractures of long bones. J Bone Joint Surg Am. 1976;58:453-8.

Cite this article as: Ali MA, Adimoolam M, Banu H. Primary intra medullary inter locking nailing for open tibia fractures a prospective analysis of functional and radiological outcome. Int J Res Orthop 2021;7:715-9. 